\section{A topologia das linhas aéreas no Brasil: novas lógicas do poder territorial}

Ana Paula Camilo Pereira

Unidade Universitária de Campo Grande, Universidade Estadual de Mato Grosso do Sul, Brasil.

Hervé Théry

CNRS-Creda, França / Departamento de Geografia, Universidade de São Paulo, Brasil.

Recebido: 2 de abril de 2018. Aceptado: 17 de julio de 2018.

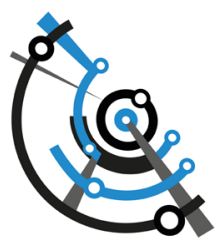

\title{
Resumo
}

Discutir as estratégias empresariais no setor de transporte aéreo brasileiro requer considerar a atuação das principais empresas do mercado: Latam, Gol, Avianca e Azul. Suas atuações estão concentradas nos principais aeroportos do país, sobretudo nos fixos aeroportuários localizados na Região Concentrada. Essa configuração territorial dos voos se constitui em uma tendência que vem desde a atuação da companhia Varig que centralizava seus voos nos principais hubs do Brasil, passando de uma base regional a ser reconhecida mundialmente antes de entrar em falência, ponto final da expansão e encolhimento de sua rede aérea. Hoje, o que temos observado é que há uma nova lógica do capital que tem redefinido esta topologia aérea dos voos com distribuição a partir dos aeroportos localizados na Região Concentrada do país. Nota-se uma rearticulação territorial, a partir de uma relativa descentralização das ligações nacionais num processo de valorização da escala regional, a exemplo da companhia Azul, que aumentou exponencialmente o serviço aéreo onde verificou uma ociosidade da demanda. Desse modo, este artigo objetiva, a partir de uma abordagem histórico-geográfica, analisar e discutir o setor aéreo brasileiro como forma de verificar de que modo a estratégia articula a dinâmica do capital à um poder territorial.

\section{The topology of airlines in Brazil: new logics of territorial power}

\author{
Abstract \\ Discussing the business strategies in the Brazilian air transport sector requires an analy- \\ sis about the performance of the main companies in this market: Latam Airlines, Gol \\ Airlines, Avianca Brazil and Azul Brazilian Airlines. The activities of these companies
}

\section{Keywords}

Air transport Territorial power Dynamics of capital Airlines Airports 
are concentrated in the main airports of Brazil, especially in the fixed airports located in the Concentrated Region of the country. The territorial configuration of flights is a trend that comes from the performance of the old company Varig Brazilian Airlines, which centralized its flights in the main hubs of Brazil, starting from a regional base until becoming recognized worldwide before going bankrupt, causing the shrinkage of its air network and defining an end point in its expansion. Today, it is observed that there is a new logic of capital that has redefined this flights aerial topology with a distribution from the airports located in the Concentrated Region of the country. There is a territorial rearticulation, based on a relative decentralization of the national connections in a process of valorization of the regional scale, like the company Azul Brazilian Airlines, that increased exponentially the service of air transport in those places where there was an underutilized demand. Thus, this article aims, based on a historical-geographical approach, to analyze and discuss the Brazilian air sector as a way to verify how the strategy articulates the dynamics of capital to a territorial power.

\section{Introdução}

As análises que tratam do setor de transporte aéreo no Brasil evidenciam, de forma unânime, o crescimento do número de passageiros, do aumento da oferta correlata a uma crescente demanda que se verifica nas diversas escalas territoriais.

De acordo com a Agência Nacional da Aviação Civil (ANAC), agência reguladora, responsável por compilar os dados estatísticos do setor aéreo no país, apesar desse crescimento, verificado a mais de uma década, ${ }^{1}$ recentemente o setor apresenta uma ligeira queda, decorrente da recessão econômica que influenciou diretamente o transporte aéreo. Conforme destaca a ANAC, no ano de 2016, o transporte aéreo registrou um total de 109,6 milhões de passageiros no país, dos quais 88,7 milhões realizaram seus deslocamentos em voos domésticos e 20,9 milhões em voos internacionais.

Dentro dessa perspectiva estatística, entender o papel das companhias aéreas é fundamental para compreender a dinâmica econômica do setor e aliado a isso a ampliação do uso do território (Santos, 1994). É analisando essa dinâmica econômica e territorial, na qual se verifica a relação entre a oferta e demanda, que podemos destacar a importância da composição das malhas aéreas dessas empresas e de seus interesses de ampliação territorial. Esta composição se constitui a partir de um planejamento estratégico de rotas, em outras palavras, as companhias desenham suas malhas considerando diversos fatores, tais como: demanda, concorrência, infraestrutura aeroportuária, capilaridade etc.

Tendo esta concepção, é importante compreender que a dinâmica do capital está diretamente relacionada a dinâmica territorial, uma vez que as companhias aéreas visam por meio de suas ações estratégicas concorrer pela atuação nas diferentes escalas territoriais. Estar presente em todas as escalas territoriais é fundamental para as companhias proverem uma capacidade de geração de tráfego que engendre passageiros em diferentes rotas, num processo retroalimentador.

Evidentemente que o poder de mercado é essencial nesse jogo de relações territoriais. Esse poder de mercado se estabelece no tempo e no espaço, ou seja, as companhias aéreas, quando bem-sucedidas, adquirem no decorrer do tempo um maior poder de mercado, este se confirma na medida em que a empresa expande sua atuação no mercado, ou seja, passa a atuar em diferentes escalas.

Diversas empresas nacionais já se consolidaram no mercado, com importância na escala internacional, a exemplo da Viação Aérea Rio Grandense (Varig), companhia
1. Conforme informações da ANAC (2017), esse número representou uma retração de $6,9 \%$ em comparação com o ano de 2015, a primeira queda após 13 anos consecutivos de crescimento. 
esta que em decorrência de suas escolhas estratégicas de atuação no mercado, registrou na história da aviação brasileira um período de auge, intrinsecamente relacionado ao seu poder territorial, que conheceu um período de ascensão associado a expansão da sua rede de fluxos e conexões aéreas pelo Brasil e pelo mundo e, posteriormente um momento de decadência ${ }^{2}$ em que se viu inserida num processo falimentar, resultado de suas estratégias de atuação territorial, ${ }^{3}$ que priorizaram a escala internacional ${ }^{4}$ em detrimento das escalas nacional e regional.

Assim, numa perspectiva histórico-geográfica de análise do setor, apresentamos este artigo com a seguinte composição: primeiramente tratamos da atuação de uma das principais e mais promissoras companhia aérea do mercado brasileiro, com foco para seu desenvolvimento estratégico, em que se agrega uma perspectiva geopolítica associada às estratégias de mercado que, favoreceram seu auge, mas também cooptaram para sua decadência.

Após, apresentamos uma análise que retrata a articulação entre a criação de estratégias do capital empresarial e a busca por um poder territorial, conferindo uma abordagem que retrata as lógicas estratégicas na redefinição da topologia das linhas aéreas das principais companhias aéreas líderes no mercado brasileiro na atualidade.

Associado a essa abordagem, destacamos cartograficamente como a malha aérea das principais companhias que atuam no mercado aéreo brasileiro tem se redefinido, o que é resultado da concorrência na escala nacional, mas sobretudo devido a expansão regional da companhia Azul, que reconfigurou uma nova lógica da topologia aérea no território brasileiro, provocando a redefinição dos principais hubs no sentido de criar novas ligações fora da Região Concentrada (Santos e Silveira, 2004) do Brasil.
2. De líder do mercado no final dos anos de 1990 , com mais de 50\% de participação no mercado doméstico, a VARIG teve, em 2006, seu market share reduzido para $2 \%$, fator que se somava a diminuição da taxa de ocupação de seus aviões e ao aumento de sua dívida (Camilo Pereira, 2016).

3. Convém notar que no mesmo período nasceram a SCADTA Sociedad Colombo-Alemana de Transportes Aéreos (Colômbia, 1919), o Lloyd Aéreo Boliviano (Bolívia, 1925) e a Aeroposta Argentina S.A. (1927), assim como a Nyrba e a Panagra no decorrer dos anos de 1930 (Argentina). A correlação é clara nas concessões de franquia e na atmosfera favorável ao desenvolvimento nacional do transporte aéreo". 4. Guaracy (2003: 250), destaca que nesse período as estratégias das grandes companhias de bandeira nacional estavam voltadas para o mercado externo, “a VARIG mantinha sua política de investir nas linhas internacionais, com dificuldade para enfrentar as companhias aéreas estrangeiras".

\section{Da base regional ao mundo e à falência: expansão e encolhimento da rede aérea da Varig}

Começando com uma base regional no Rio Grande do Sul, a Varig foi a única companhia aérea brasileira a operar em todos os continentes, incluindo a Ásia e a África, até que dificuldades de gestão e a concorrência de novas companhias mais ágeis a levassem ao encolhimento da sua rede e finalmente à falência.

\section{Anos iniciais}

A primeira rota aérea da Varig, inaugurada no dia 3 de fevereiro de 1927, era a conhecida como "Linha da Lagoa", pois ligava as cidades de Porto Alegre, Pelotas e Rio Grande, com hidroaviões que decolavam e pousavam na Lagoa dos Patos. 


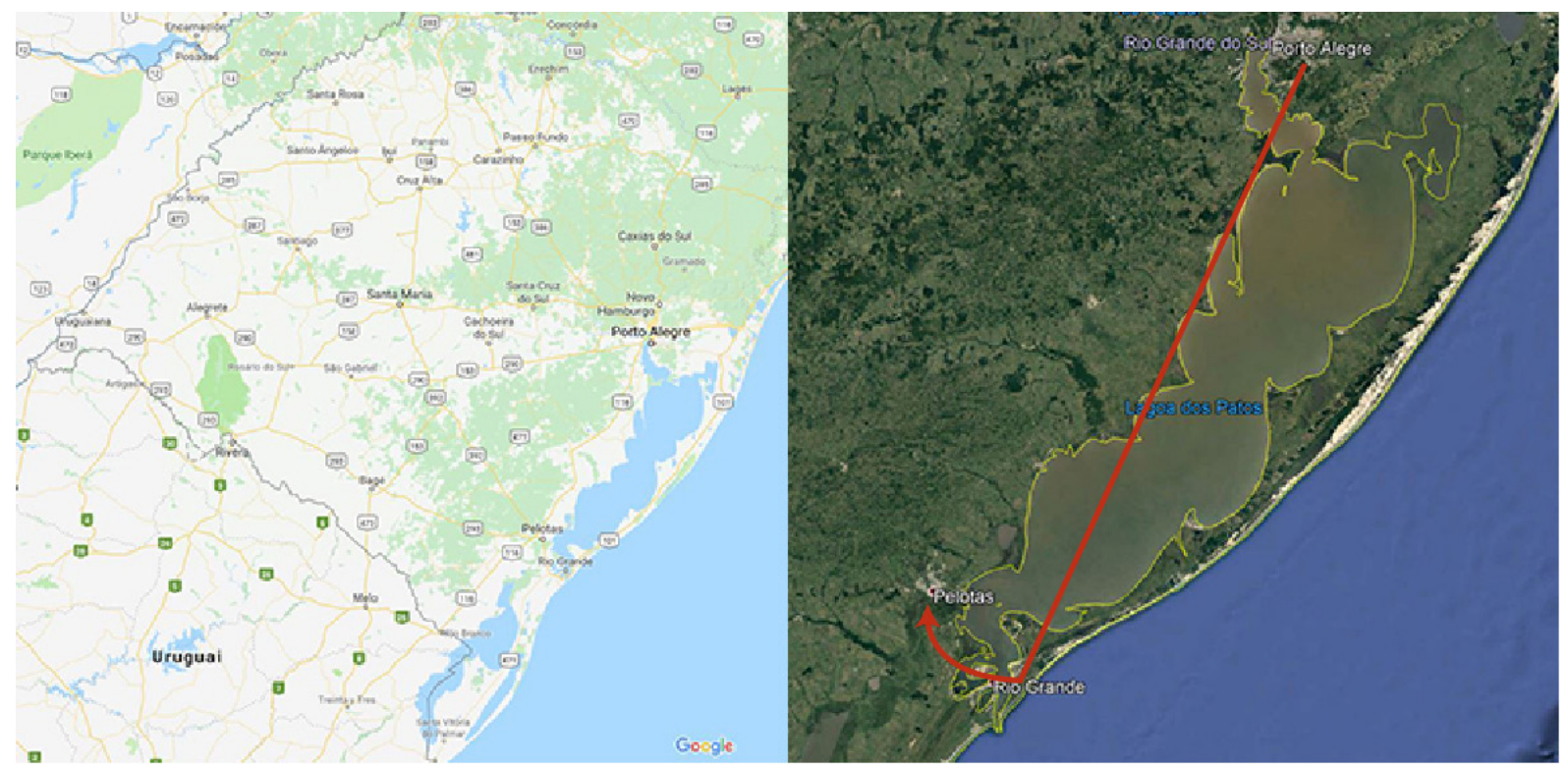

Figura 1. A primeira linha da Varig (1927). Fonte: Rotas da Varig.

Ainda nos anos 1930, a Varig expandiu suas rotas para o interior do Rio Grande do Sul. Com a compra de aeronaves pousando em terra firme em vez de hidraviões, a companhia estendeu suas rotas para cidades como Livramento, Santa Cruz, Cruz Alta, Santana do Livramento Uruguaiana, Bagé, Santa Maria, Santo Ângelo, Rosário do Sul, Passo Fundo e Caxias.

Na década de 1940, ela expandiu suas rotas para além das fronteiras do Rio Grande do Sul, chegando a cidades dos estados de Santa Catarina, Paraná, São Paulo e Rio de Janeiro. Em 1942 ela inaugurou a sua primeira rota internacional, ligando Porto Alegre a Montevidéu, e pouco depois para Buenos Aires. 


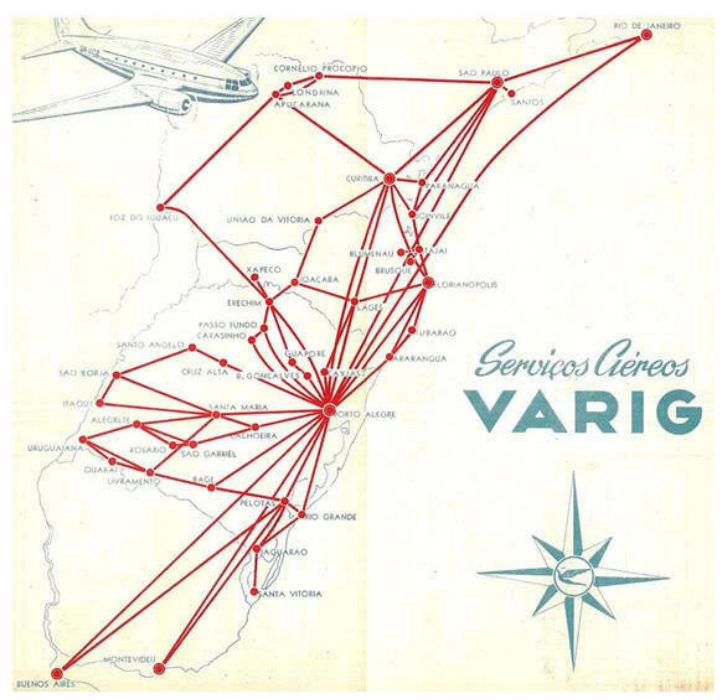

Figura 2. A rede da Varig (1940). Fonte: http://www.aviacaocomercial.net/rotasvarig.htm

\section{Expansão}

A aquisição da Aero Gal, em 1952, possibilitou estender as linhas para o Nordeste, chegando Vitória (ES), Salvador (BA), Aracajú (SE), Penedo (AL), Maceió (AL), Recife (PE), João Pessoa (PB), Natal (RN), Fortaleza (CE) e São Luís (MA).

Em 1955 a linha internacional foi expandida até os Estados Unidos, criando uma rota Buenos Aires (Argentina) - Montevidéu (Uruguai) - Porto Alegre (RS) - São Paulo (SP) -Rio de Janeiro (RJ) - Belém (PA) - Trujillo (Santo Domingo, República Dominicana) - Nova York (EUA). Na volta se fazia a rota Port of Spain (Trindade e Tobago) - Rio de Janeiro - São Paulo - Porto Alegre - Montevidéu - Buenos Aires. Em 1959 foi posto em serviço uma Caravelle da Sud-Aviation, o primeiro jato do Brasil, e tempo da viagem Rio - Nova York foi reduzido de 25 horas para 14 horas. Em 1960, com os Boeing 707-441 a ligação era feita em apenas 9 horas, sem escalas.
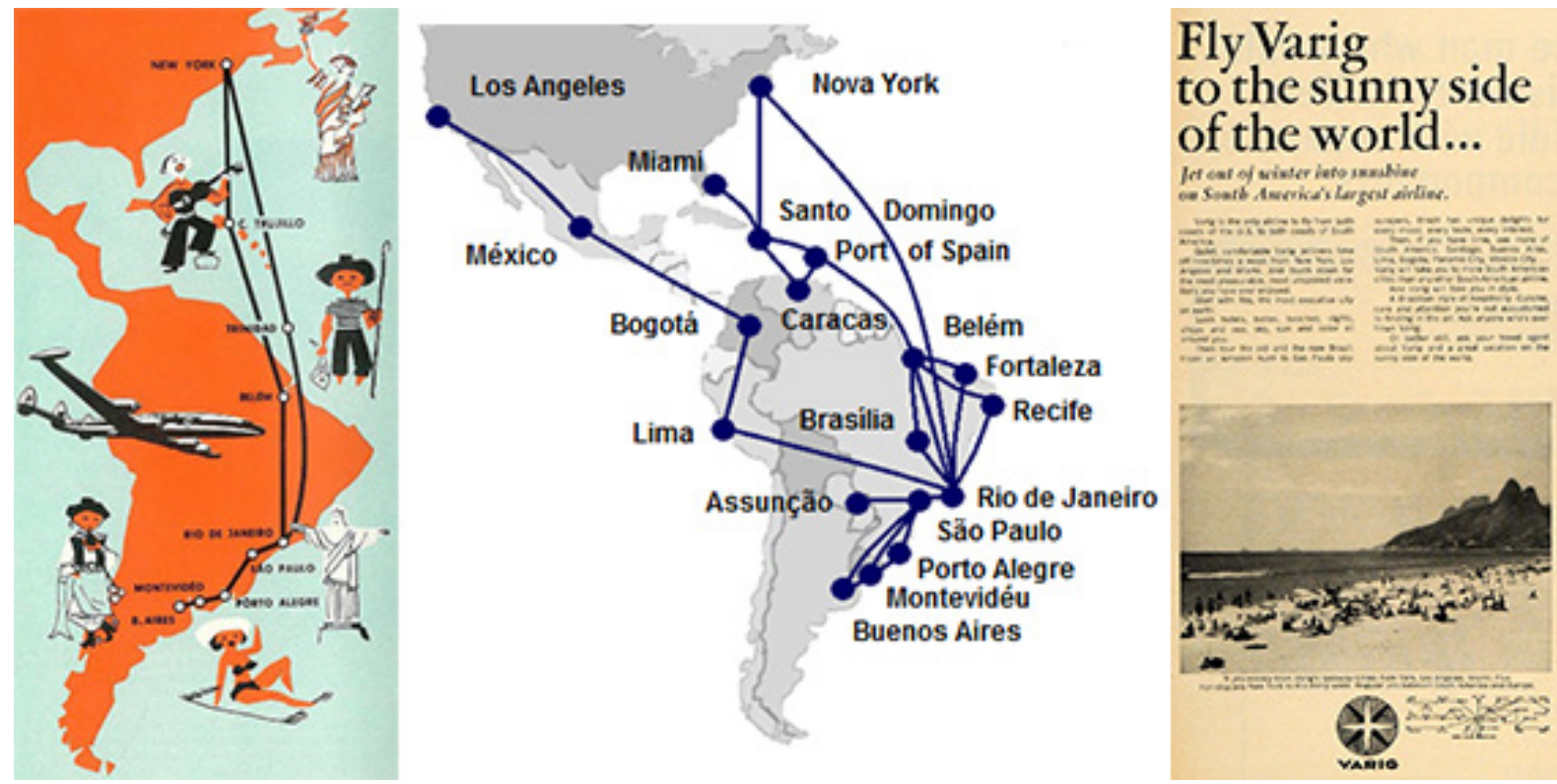

Figura 3. A rede da Varig (1950). Fonte: http://www.varig-airlines.com/pt/so.htm 
Depois da aquisição do consórcio Real-Aerovias-Nacional, em 1961, a Varig passou a operar para mais de 90 cidades no Brasil. No mercado internacional, a compra possibilitou a Varig chegar em Lima, Bogotá, Caracas, Cidade do México, Miami e Los Angeles.

Em 1965 ela assumiu as rotas da Panair do Brasil ${ }^{5}$ para Europa, passando a operar para Lisboa, Madrid, Monróvia, Ilha do Sal, Dakar, Beirute, Roma, Milão, Zurique, Paris, Frankfurt, Londres e Santiago do Chile. Em 1968, a Varig expandiu ainda mais as suas rotas internacionais, com voos para Copenhagen (com escala em Roma) e Tokyo (com escalas em Lima, Los Angeles e Honolulu). A intenção era conseguir dar a volta ao mundo como já faziam empresas aéreas como a Pan Am, e a rota para o Japão era um passo nesse sentido.

Nos anos de 1970, houve uma grande mudança no mercado doméstico brasileiro. Com a introdução dos jatos, as rotas regionais foram abandonadas e as companhias aéreas centralizaram suas rotas nos grandes centros. Em 1976 a Varig criou a sua subsidiária Rio Sul para rotas regionais nos estados do Rio Grande do Sul, Santa Catarina, Paraná e Rio de Janeiro e abandonou de vez as rotas regionais, ${ }^{6}$ passando a operar somente nas grandes cidades.

Porém, a companhia continuou a sua política de expansão para as linhas internacionais e lançou voos para África, além de ampliar a presença na América Latina, EUA e Europa. Em 1970 foi inaugurada a linha Rio de Janeiro - Luanda - Johanesburgo e a compra da Cruzeiro, em 1975, permitiu que ela expandisse as suas rotas na América do Sul para Bolívia, Equador, Guiana Francesa e Suriname.

Os anos de 1980, a década perdida, viram uma consolidação das rotas já operadas e uma pequena expansão no número de destinos nacionais, puxado principalmente pela expansão da Rio Sul, e de destinos internacionais como Iquitos, São José, Amsterdam, Toronto e Montreal.

No início dos anos de 1990, a Varig alcançou o maior número de destinos internacionais servidos em toda a sua história com o lançamento das rotas para Chicago, Atlanta, Washington, Cancun, Nagoya, Bangkok, Hong Kong e Munique.
5. Empresa norte americana que nos anos de 1940 chegou a ser considerada uma das principais companhias aéreas do mundo.

6. Na década de 1970 foram criados os Sistemas Integrados de Transporte Aéreo Regional (SITAR) que era uma política pública do Estado juntamente com o Ministério da Aeronáutica que previa o regime de exclusividade para cinco empresas aéreas de transporte aéreo no Brasil, com o objetivo de dinamizar o serviço em regiões antieconômicas, com isso atendia as localidades de baixo e médio potencial de tráfego, ampliando a cobertura do transporte aéreo.

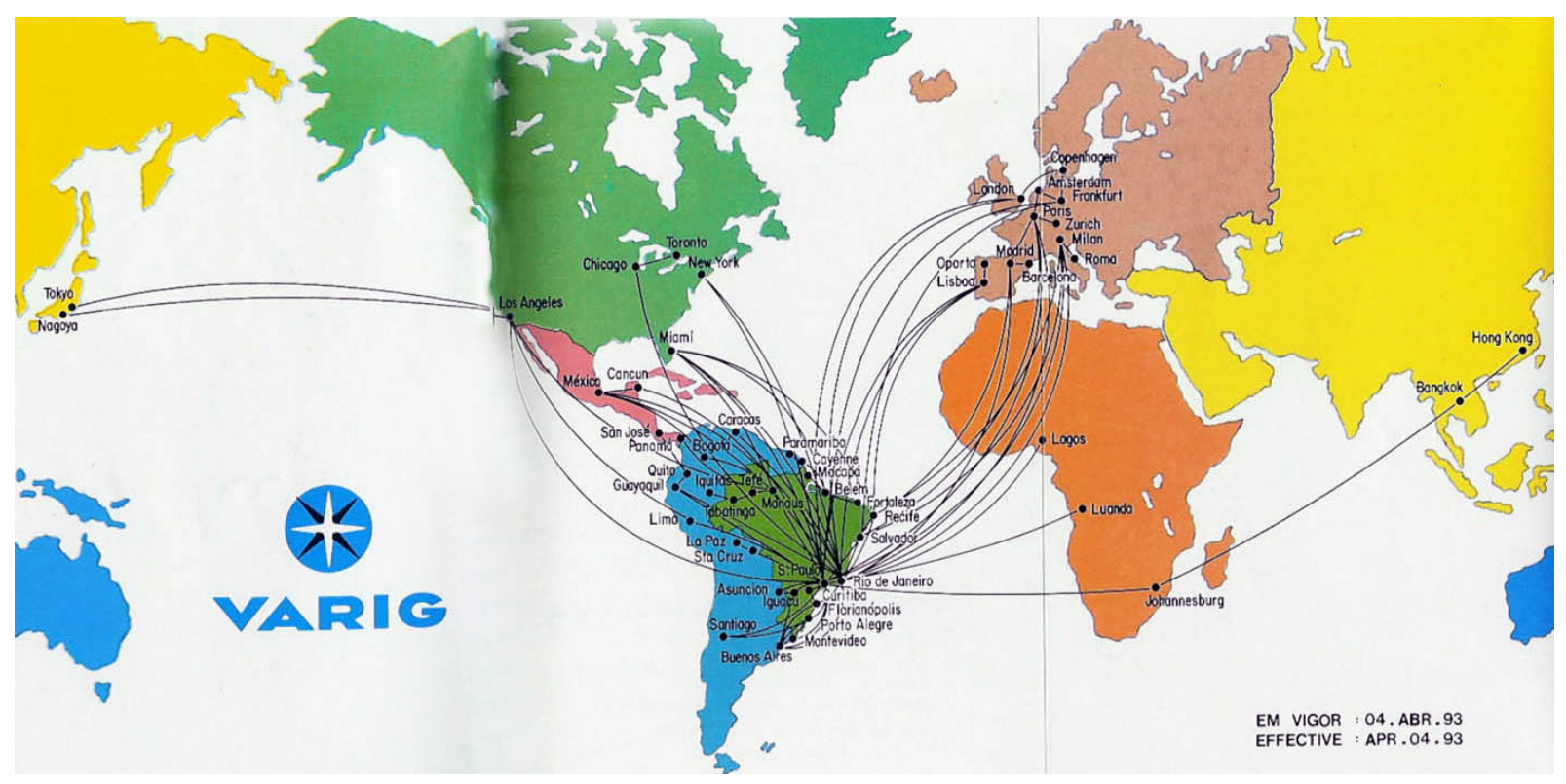

Figura 4. A rede da Varig (1990). Fonte: Rotas da Varig.

No entanto, esta década foi também marcada pelo início das dificuldades da Varig. Com a desregulamentação do mercado de aviação comercial brasileiro surgiram 
novas companhias, principalmente regionais e charters, a Varig perdeu o monopólio das rotas internacionais e teve que competir não só com a Vasp e a Transbrasil, mas também com várias outras companhias estrangeiras que foram autorizadas a voar para o Brasil. Ela começou a dar prejuízo e teve que se reestruturar, reduzindo sensivelmente a sua rede.

Como fator adicional a colocar à tona toda ineficiência do setor, o cenário macroeconômico brasileiro e mundial aprofunda sua crise a partir de 1999. Em decorrência, a taxa de câmbio do dólar americano sai de cerca de R\$1,20, em dezembro de 1998, elevando-se até R\$3,63, em dezembro de 2002. Nesse período a inflação acumulada em 12 meses passa de 2,5\% para 13,8\% e a taxa de crescimento real do Produto Interno Bruto brasileiro cai de 4,4\% para 1,5\% ao ano. A conjunção dos fatores desencadeou o fim das operações internacionais da VASP em setembro de 2000, o encerramento das atividades da TRANSBRASIL em dezembro de 2001 e a situação pré-falimentar da VARIG em 2002 (Moreira, 2007:9).

Os anos 2000 marcaram o fim da Varig. Após os atentados de 11 de setembro de 2001, a aviação comercial foi atingida no mundo inteiro por uma crise aguda, e nesta mesma época foram fundadas e expandidas duas grandes concorrentes da Varig, a atual Latam e a Gol.

Em 2005, a Varig entrou com um pedido de recuperação judicial, em 2006 foi dividia em duas empresas e leiloada. A VRG Linhas Aéreas, conhecida coloquialmente como a Nova Varig, a parte economicamente saudável da companhia, continuou a operar com a licença da Varig.

No ano de 2007, ela foi comprada pela Gol, e prosseguiu independente por algum tempo, a sua marca ainda podia ser vista até abril de 2014, quando as últimas aeronaves foram pintadas nas cores da GOL. Conforme, Camilo Pereira (2016:100) destaca: "a VARIG existe hoje apenas na história e pulsando dentro do coração da GOL”.

Retraçando esta epopeia de conquista do mundo, o Quadro 1 e a Figura 5 mostram a expansão progressiva e o encolhimento final da rede da Varig, enquanto a Figura 6 indica quais cidades foram permanentemente presentes nela, enquanto outras apenas permaneceram nela em algumas décadas. E finalmente a Figura 7 mostra que a Latam e a Gol assumiram apenas uma pequena parte da herança da Varig, deixando de lado as ambições planetárias, que não cabiam mais no novo contexto econômico do transporte aéreo mundial. 
Quadro 1. A rede da Varig (1950 - 2000). Fonte: Rotas da Varig

\begin{tabular}{|c|c|c|c|c|c|c|c|}
\hline Cidades & $\begin{array}{c}\text { Anos } \\
1950\end{array}$ & $\begin{array}{l}\text { Anos } \\
1960\end{array}$ & $\begin{array}{c}\text { Anos } \\
1970\end{array}$ & $\begin{array}{l}\text { Anos } \\
1980\end{array}$ & $\begin{array}{l}\text { Anos } \\
1990\end{array}$ & $\begin{array}{l}\text { Anos } \\
2000\end{array}$ & Total \\
\hline Buenos Aires & 1 & 1 & 1 & 1 & 1 & 1 & 6 \\
\hline Montevidéu & 1 & 1 & 1 & 1 & 1 & 1 & 6 \\
\hline New York & 1 & 1 & 1 & 1 & 1 & 1 & 6 \\
\hline Assunção & & 1 & 1 & 1 & 1 & 1 & 5 \\
\hline Bogotá & & 1 & 1 & 1 & 1 & 1 & 5 \\
\hline Caracas & & 1 & 1 & 1 & 1 & 1 & 5 \\
\hline Copenhagen & & 1 & 1 & 1 & 1 & 1 & 5 \\
\hline Frankfurt & & 1 & 1 & 1 & 1 & 1 & 5 \\
\hline Lima & & 1 & 1 & 1 & 1 & 1 & 5 \\
\hline Lisboa & & 1 & 1 & 1 & 1 & 1 & 5 \\
\hline London & & 1 & 1 & 1 & 1 & 1 & 5 \\
\hline Los Angeles & & 1 & 1 & 1 & 1 & 1 & 5 \\
\hline Madrid & & 1 & 1 & 1 & 1 & 1 & 5 \\
\hline México & & 1 & 1 & 1 & 1 & 1 & 5 \\
\hline Miami & & 1 & 1 & 1 & 1 & 1 & 5 \\
\hline Milão & & 1 & 1 & 1 & 1 & 1 & 5 \\
\hline Paris & & 1 & 1 & 1 & 1 & 1 & 5 \\
\hline Santiago & & 1 & 1 & 1 & 1 & 1 & 5 \\
\hline Tokyo & & 1 & 1 & 1 & 1 & 1 & 5 \\
\hline Roma & & 1 & 1 & 1 & 1 & & 4 \\
\hline Zurich & & 1 & 1 & 1 & 1 & & 4 \\
\hline Amsterdam & & & & 1 & 1 & 1 & 3 \\
\hline Johanesburgo & & & 1 & 1 & 1 & & 3 \\
\hline La Paz & & & & 1 & 1 & 1 & 3 \\
\hline Luanda & & & 1 & 1 & 1 & & 3 \\
\hline Oporto & & & 1 & 1 & 1 & & 3 \\
\hline Panamá & & 1 & & 1 & 1 & & 3 \\
\hline Santa Cruz de La Sierra & & & & 1 & 1 & 1 & 3 \\
\hline Barcelona & & & & 1 & 1 & & 2 \\
\hline Cancun & & & & & 1 & 1 & 2 \\
\hline Cayenne & & & & 1 & 1 & & 2 \\
\hline Guayaquil & & & & 1 & 1 & & 2 \\
\hline Lagos & & & & 1 & 1 & & 2 \\
\hline Nagoya & & & & & 1 & 1 & 2 \\
\hline Paramaribo & & & & 1 & 1 & & 2 \\
\hline Quito & & & & 1 & 1 & & 2 \\
\hline São José & & & & 1 & 1 & & 2 \\
\hline Toronto & & & & 1 & 1 & & 2 \\
\hline Cidade do Cabo & & & 1 & 1 & & & 2 \\
\hline Munich & & & & 1 & & 1 & 2 \\
\hline Port of Spain & 1 & & & 1 & & & 2 \\
\hline Santo Domingo & 1 & 1 & & & & & 2 \\
\hline Atlanta & & & & & 1 & & 1 \\
\hline Bangkok & & & & & 1 & & 1 \\
\hline Chicago & & & & & 1 & & 1 \\
\hline Hong Kong & & & & & 1 & & 1 \\
\hline Orlando & & & & & 1 & & 1 \\
\hline Washington & & & & & 1 & & 1 \\
\hline Abidjan & & & & 1 & & & 1 \\
\hline Aruba & & & & & & 1 & 1 \\
\hline Beirute & & 1 & & & & & 1 \\
\hline Bridgetown & & & & 1 & & & 1 \\
\hline Córdoba & & & & & & 1 & 1 \\
\hline Geneva & & & 1 & & & & 1 \\
\hline Ilha do Sal & & 1 & & & & & 1 \\
\hline Maputo & & & & 1 & & & 1 \\
\hline Monróvia & & 1 & & & & & 1 \\
\hline Montreal & & & & 1 & & & 1 \\
\hline Punta Del Este & & & & & & 1 & 1 \\
\hline Total & 5 & 26 & 26 & 43 & 44 & 28 & \\
\hline
\end{tabular}


Destinos nos anos 1950

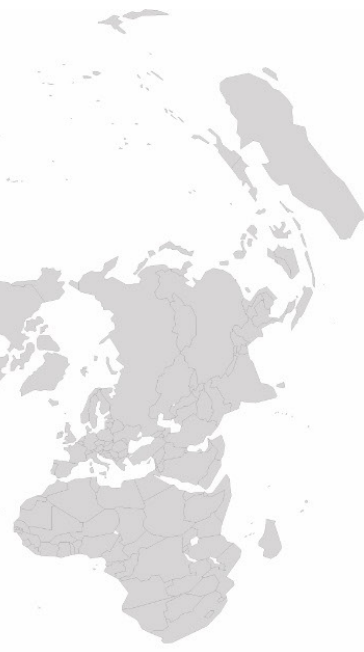

Destinos nos anos 1970

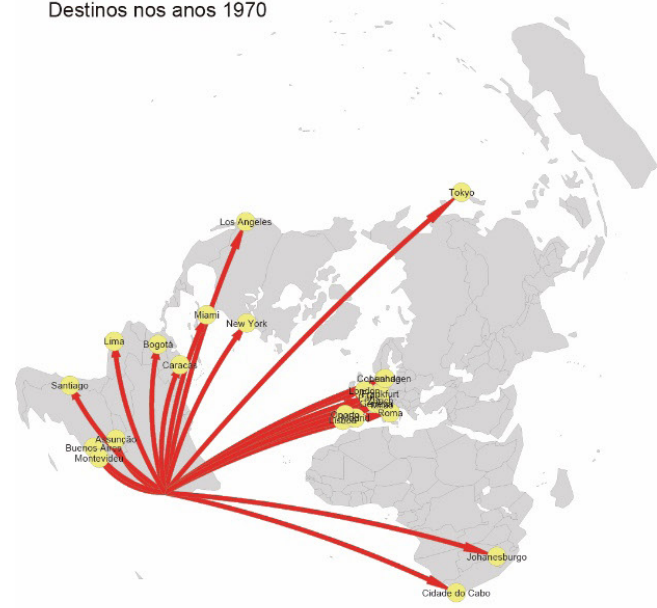

Destinos nos anos 1990

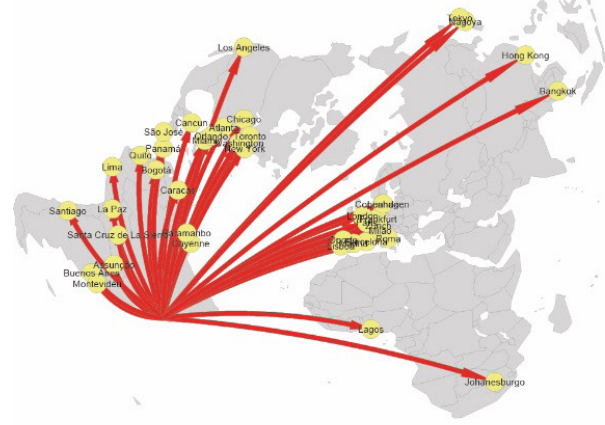

Fonte. Rotas da Varig

http://www.varig-airlines.com/pt/rotas.htm

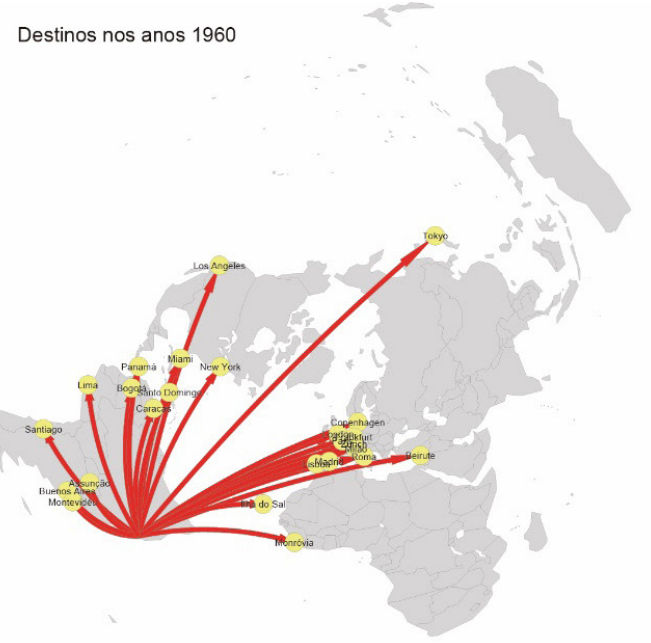

Destinos nos anos 1980

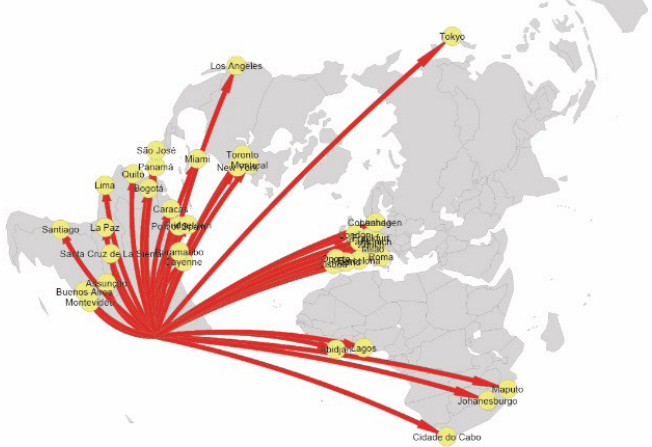

Destinos nos anos 2000

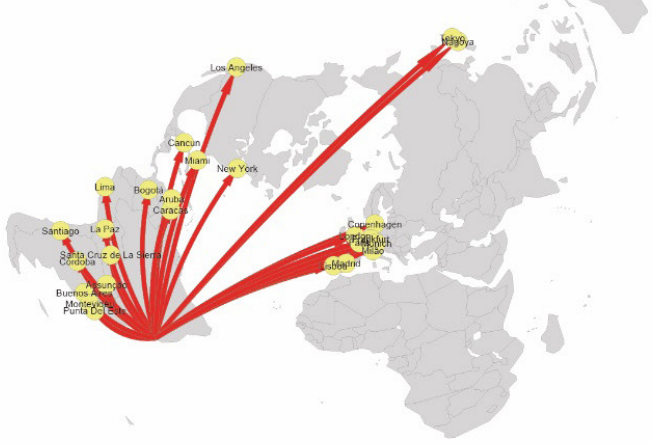

Carte réalisée avec Cartes \& Données - ๑) Articque

Figura 5. Expansão e encolhimento da rede da Varig (1950 - 2000). Fonte: Rotas da Varig 


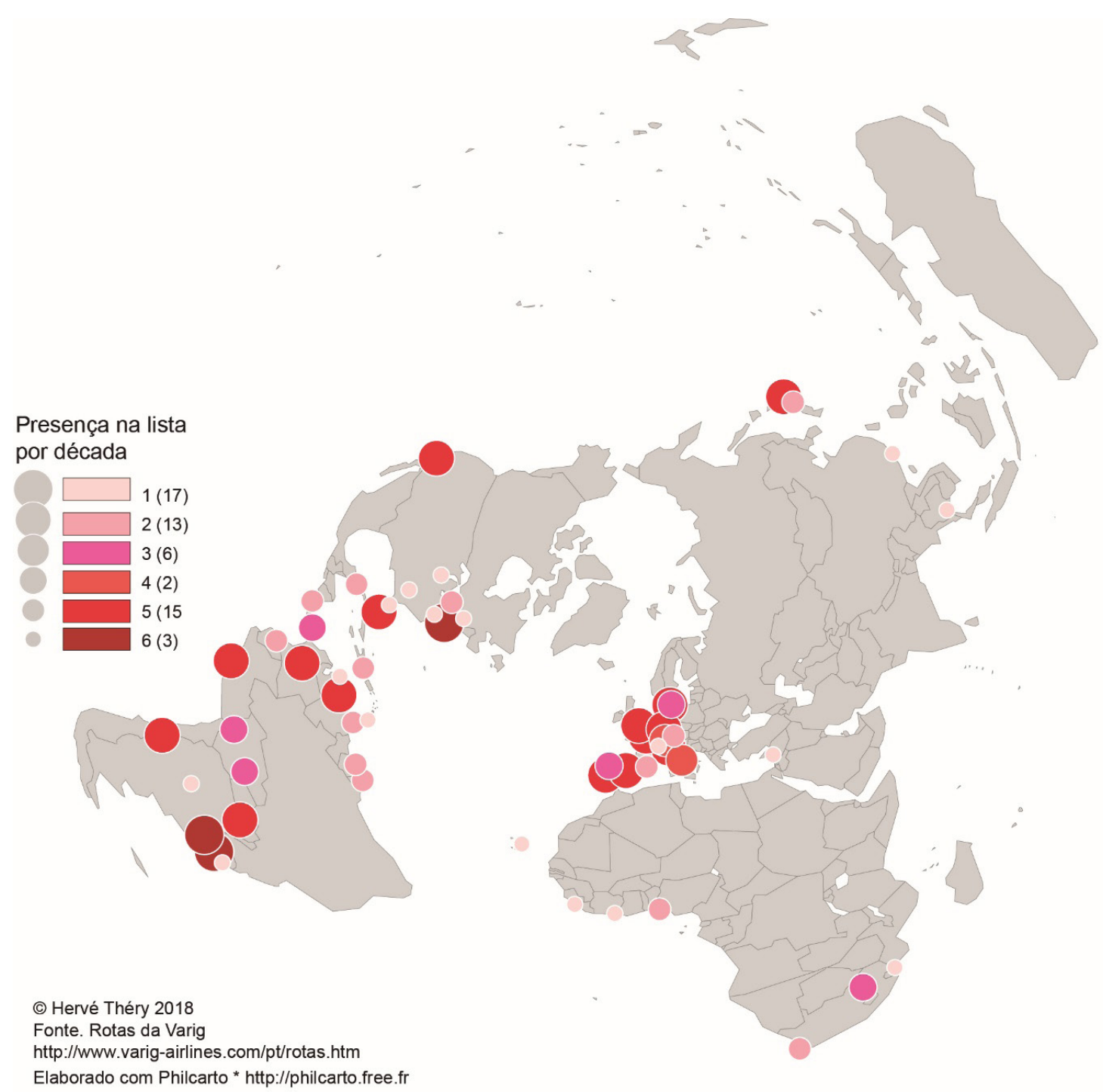

Figura 6. Presença das cidades ao longo da história da Varig (1950 - 2000). Fonte: Rotas da Varig 


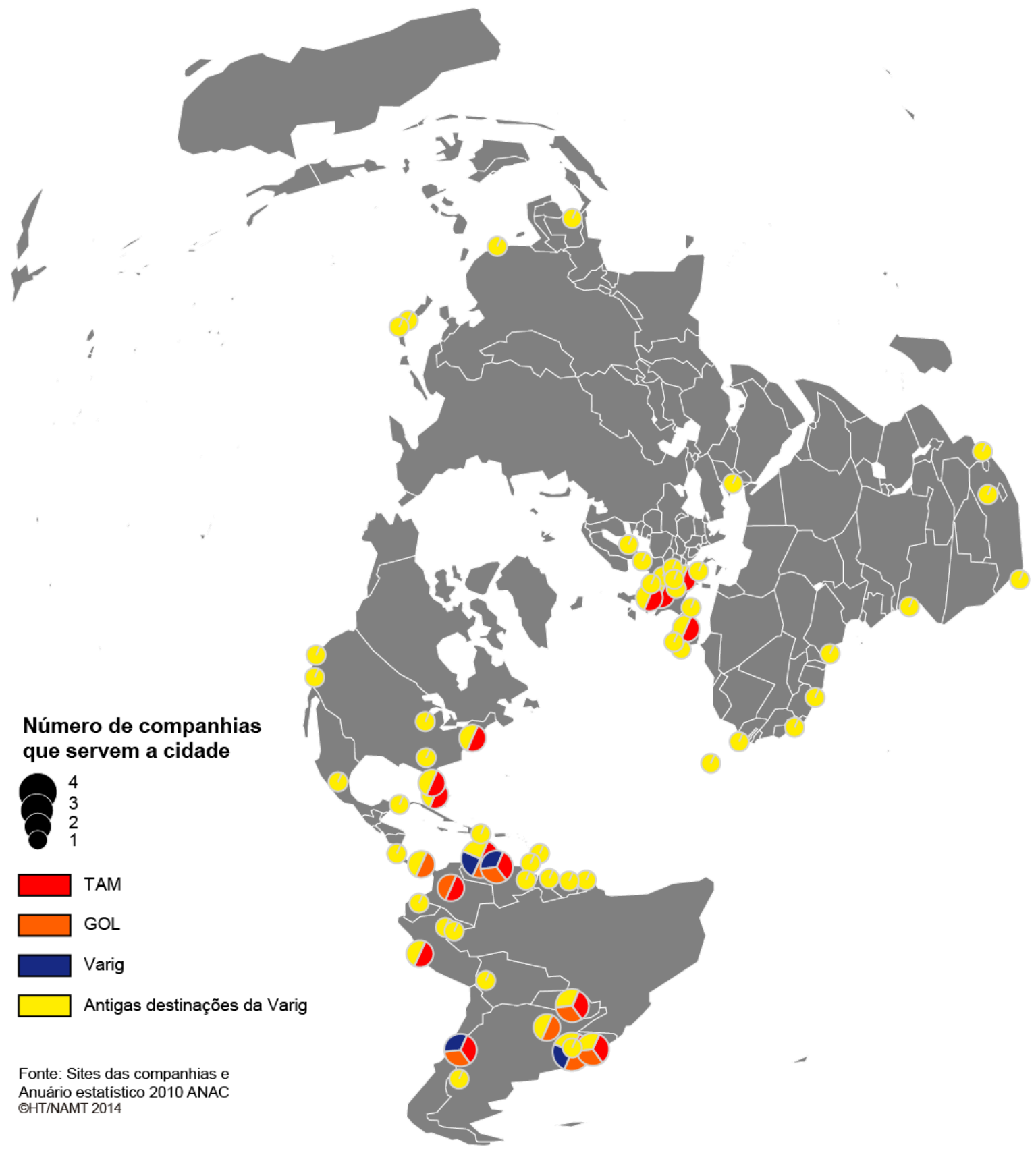

Figura 7. A herança da Varig (2010). Fonte: Rotas da Varig e Agência Nacional da Aviação Civil (ANAC)

Nessa perspectiva histórico-geográfica sobre a companhia Varig, importa compreender que a estratégia de atuação territorial é essencial para se consolidar no mercado, independentemente da escala. Contudo, a prerrogativa dessa atuação não é apenas se consolidar, mas sobretudo manter-se consolidada e, nessa compreensão a escala nacional é crucial no jogo de relações estratégicas.

A companhia Varig é um exemplo substancial de que as estratégias territoriais se constituem, no mercado na aviação comercial, um desenlace supremo na articulação entre o poder territorial e o poder do capital. A indissociabilidade entre esses poderes nos leva a compreender as lógicas estratégicas da atualidade no setor aéreo. 


\section{Poder territorial e poder do capital: lógicas estratégicas na redefinição da topologia das linhas aéreas}

Uma das características mais expressivas do setor de transporte aéreo é sua capacidade de ser produto de um serviço cada vez mais popular, o que é reflexo do aumento dos fluxos, e ao mesmo tempo, se constitui como possibilidade de ser expandir cada vez territorialmente, o que pode ser compreendido pela expansão do processo de mundialização do capital (Chesnais, 1996), que se estende de forma pujante naqueles territórios que interessam ao capital, independentemente da escala geográfica.

O território que interessa ao capital é determinado pela essencialidade das escolhas estratégicas dos agentes econômicos que estão envolvidos nesse mercado. Em outras palavras, o planejamento estratégico das companhias aéreas, numa associação que ora se dá com o Estado, ora com outras companhias, se faz fundamental nessa conexão entre a determinação de um poder territorial articulado a um poder do capital.

Nessa lógica, três pontos são essenciais para se examinar: a estratégia, o poder do capital e o poder territorial. Tendo esses termos como consoantes desse processo, destacamos: 1. O que é a estratégia. 2. Como a estratégia pode definir ou ser definida pelo interesse do capital no uso do território. 3. De que modo a estratégia e o poder do capital impetram o poder territorial.

Para Porter (1986), a estratégia competitiva pode ser entendida a partir de posicionamentos ofensivos ou defensivos para criar uma situação em que se verifica uma vantagem em um determinado setor, a qual o autor preconiza a determinação de um conjunto de forças competitivas que podem incrementar um retorno superior ao investimento. Leroy (2004: 27) salienta que: "a estratégia consiste na busca de uma vantagem concorrencial significativa, durável e defensável".

Em tese, para além de uma análise estática sobre os modelos conceituais de mercado, que são verificados numa relação entre custo, preço limite, rendimento, mensuração de custo/benefício etc., nosso objetivo é compreender a ação estratégica do capital na relação com os efeitos territoriais.

Portanto, o que nos interessa entender, a partir de uma perspectiva geográfica, é que a estratégia se faz a partir de uma ação competitiva planejada por um agente econômico com o objetivo de obter uma vantagem de mercado e deter um poder territorial, que no caso é analisado pelo setor de transporte aéreo.

Esta estratégia pode ser definida ou define o interesse do poder do capital, entendido aqui, como as companhias aéreas que atuam no mercado. Nesse sentido, uma estratégia é planejada de acordo com as necessidades/interesses das empresas delinearem suas marcas no mercado. Um exemplo dessa relação entre a estratégia e o poder do capital se configura na definição da malha aérea de cada companhia.

Traça-se um planejamento de malha em uma determinada escala/aeroporto/lugar se estrategicamente for interessante ao capital empresarial, ou seja, se trará uma vantagem competitiva frente aos demais concorrentes.

Essa vantagem competitiva explica nosso terceiro e último ponto, ou seja: de que modo a estratégia e o poder do capital impetram o poder territorial. É possível observar que as companhias aéreas buscam irrefreavelmente estar presentes nas diversas escalas territoriais ${ }^{7}$ (regional, nacional e, sobretudo internacional), numa lógica hierárquica das mesmas. Na medida em que seus interesses são planejados estrategicamente e 
executados territorialmente, as companhias aéreas ampliam o poder territorial (ou o que alguns autores definem como market share (participação de mercado). Camilo Pereira (2016), destaca que:

Ao efetuar uma análise correlacional entre o capital e o território, não se busca verificar uma relação hegemônica, mas elucidar a indissociabilidade entre ambos. De certa forma, ramo a ramo, setor a setor, segmento a segmento, configuram seus interesses particulares, induzem estratégias individuais ou coletivas, instigam a rivalidade e para que essa dinâmica tenha resultado, emerge a necessidade de criar, desenvolver estratégias e sustentar vantagens competitivas e comparativas (Camilo Pereira, 2016:31).

Dadas estas conotações teóricas, atribuímo-las a uma perspectiva prática, ou seja, como podemos compreender essa relação entre o planejamento estratégico - poder do capital - poder territorial.

Na prática podemos observar como a redefinição da topologia das malhas aéreas das principais companhias aéreas brasileiras tem projetado uma rearticulação aérea que não necessariamente se centraliza na Região Concentrada (Santos e Silveira, 2004). Tal fato é resultado de uma dinâmica estratégica de reconfiguração e valorização da escala regional realizada desde a entrada da Azul no mercado aéreo brasileiro.

\section{A relativa descentralização aeroviária: quando a estratégia territorial voa mais alto}

O setor aéreo brasileiro na atualidade concentra-se na atuação de quatro grandes players do mercado aéreo brasileiro: Latam, Gol, Avianca e Azul. Historicamente, essas companhias centralizaram suas rotas nos principais hubs aeroportuários do Brasil, definidos pelos aeroportos de Congonhas (São Paulo), Cumbica (Guarulhos-SP), Viracopos (Campinas-SP), Galeão-Tom Jobim e Santos Dumont (Rio de Janeiro) e Brasília. Conforme seguem os mapas a seguir: 

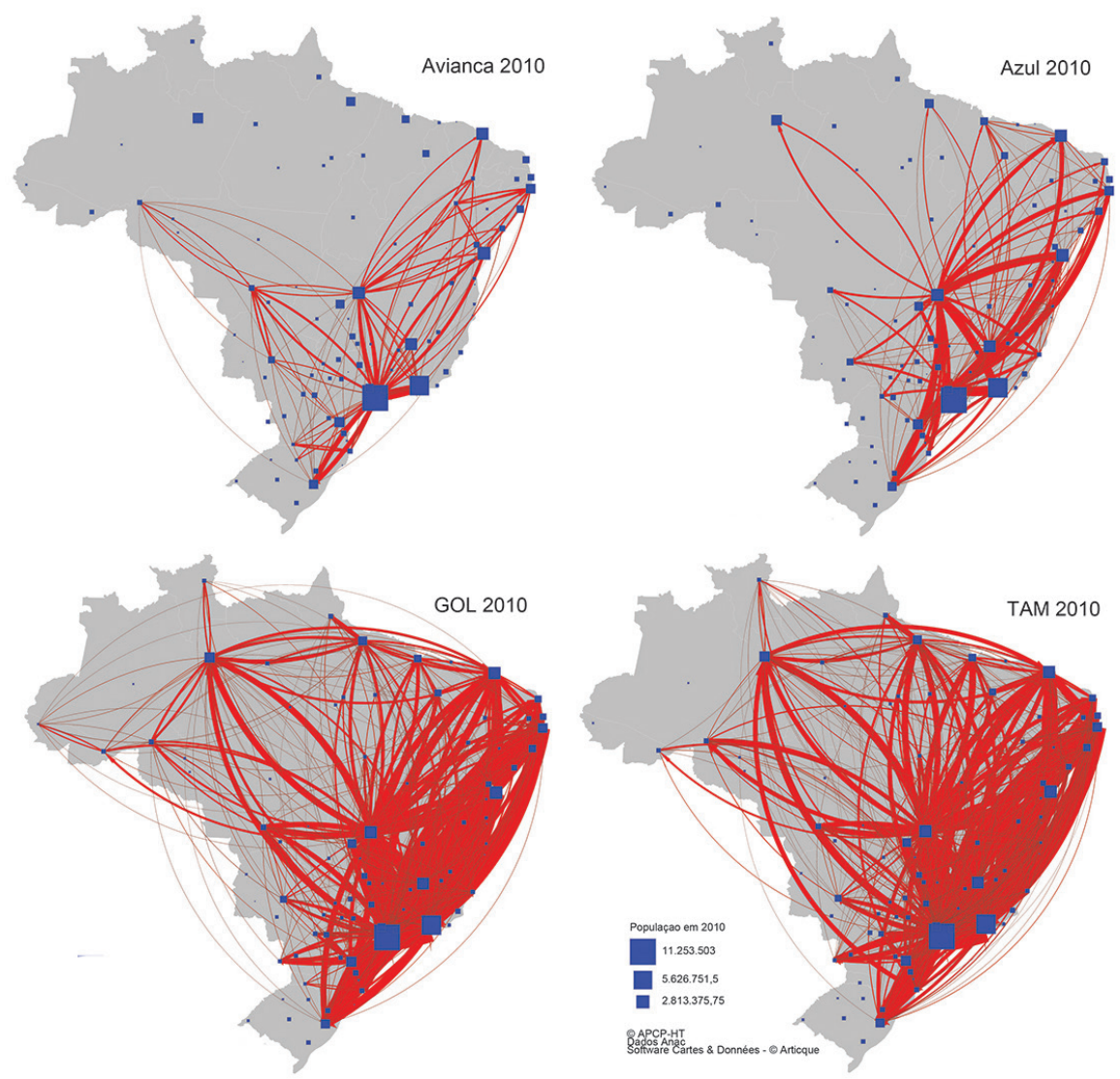

Figura 8. Malha de atuação nacional por empresa (2010). Fonte: Agência Nacional da Aviação Civil.

A partir dos mapas das companhias aéreas ilustradas nota-se que no ano de 2010 havia uma centralização dos voos na Região Concentrada, na faixa litoral, o que se justifica pelo maior contingente populacional nessa área, o que reflete um maior deslocamento de passageiros e também porque a localização do sistema aeroportuário está relacionada à maior aglomeração urbana, uma vez que o tráfego aéreo brasileiro revela, de maneira extremamente nítida, as redes hierarquizadas, que conforme destaca Théry (2003:19): "os mapas de fluxos desenham de maneira muito clara as redes hierarquizadas refletindo a estrutura centralizada do país”.

Esta estruturação centralizada do país ainda se conserva na atualidade, priorizando uma pujança econômica aos principais centros urbanos do país, com destaque para São Paulo, Rio de Janeiro e Brasília. Contudo, o setor aéreo nos mostra certa redefinição dessa lógica, fomentando uma relativa descentralização dos principais hubs brasileiros.

Essa reconfiguração dos voos no Brasil, que até certo ponto, podemos dizer que é uma redefinição logística, se deu com a entrada da Azul no mercado nacional. A estratégia da companhia se baseou na distribuição da malha de voos mediante uma perspectiva que se deu em termos territoriais e de ociosidade de frequências. Em outras palavras, buscou valorizar o uso do território sem necessariamente articulá-lo a Região Concentrada. $^{8}$

8. Essa relativa descentralização da Região Concentrada não significa que a companhia Azul não tinha/tem interesse nos principais hubs nacionais. O que queremos destacar é que sua estratégia territorial de expansão a partir da escala regional constituiu numa reconfiguração das malhas aéreas das companhias do setor. 
Para Camilo Pereira (2016:55):

A companhia aérea AZUL também reestruturou parte da dinâmica territorial, ao desenvolver esta estratégia de diversificação. Ao mesmo tempo em que a empresa aérea adotou uma nova base de operações, diversificou a malha de voos que era tradicional no país, ou seja, aquela que ligava os principais e mais movimentados aeroportos, com isso passou a oferecer múltiplos destinos, até então não explorados ou pouco explorados pelas duas grandes companhias aéreas. A lógica de reprodução capitalista impõe que quanto maior o número de ligações aéreas uma empresa aérea possui, maior seu poder territorial de penetração no mercado, o que também representa maior market share, ou seja, essa relação entre área de atuação territorial e poder de mercado é qualificada pelas ligações aéreas, pela malha de voos da companhia aérea. A TAM e a GOL possuem uma adesão territorial expressiva, atendem diversificados trechos, até mesmo aqueles com menor densidade de tráfego, contudo, esses trechos geralmente concernem às ligações secundárias das empresas aéreas, fazendo com que algumas viagens tenham atéz escalas/conexões, diferente da proposta da AZUL.

Somada a esta estratégia de mercado de ampliação da escala regional, em 2012 a Azul associou-se a principal companhia aérea regional do Brasil, a Trip Linhas Aéreas. A associação entre as duas companhias aéreas permitiu formar a maior malha aérea regional da América Latina.

Essa valorização da escala regional pode ser compreendida pela comparação entre os mapas apresentados anteriormente e os mapas ilustrados a seguir. 

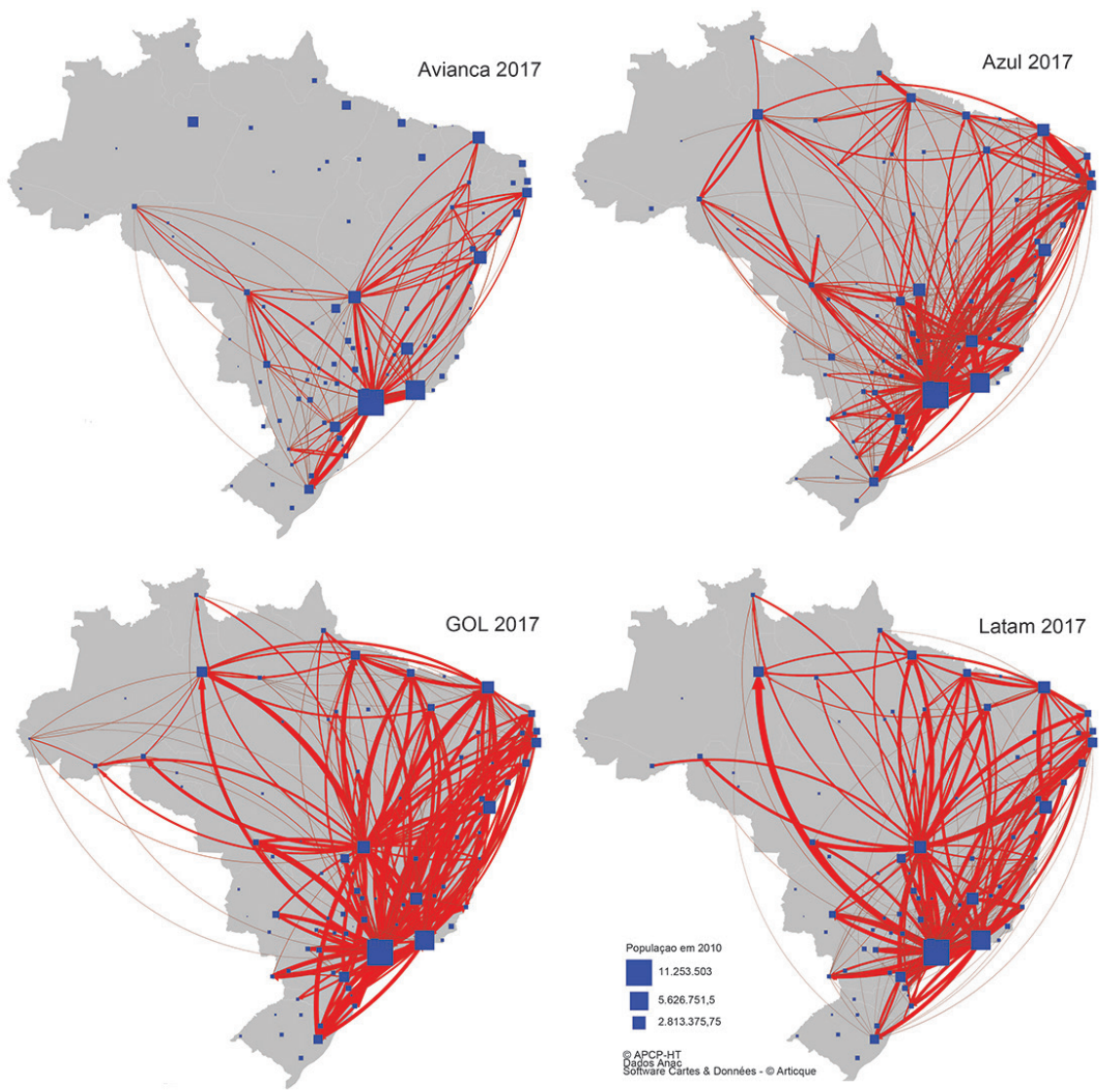

Figura 9. Malha de atuação nacional por empresa (2017). Fonte: Agência Nacional da Aviação Civil (ANAC).

Nota-se que a centralização de voos na Região Concentrada observado nos mapas de 2010 ainda está presente, mas com um diferencial, em 2017 é possível visualizar uma maior densificação dos voos pelo território nacional, com foco para as regiões Norte, Nordeste e Centro-Oeste, em razão das estratégias competitivas, que orientaram uma topologia da dinâmica aérea que priorizou os voos regionais fora da Região Concentrada, a exemplo, sobretudo da Azul.

Por outro lado, observa-se uma relativa rarefação dos voos na faixa litorânea pelas companhias tradicionais do ramo que atuavam mais fortemente no ano de 2010, como a Tam e a Gol.

Este incremento da escala regional ilustrado na Figura 9 a partir da atuação das empresas no ano de 2017 demonstra que, ainda que em menor proporção que a Azul, isso fez com que as demais companhias, Latam, Gol e Avianca também redefinissem suas lógicas territoriais a fim de estar presente na extensão do país, mantendo com isso suas marcas e respondendo com isso a competitividade gerada pela estratégia da Azul.

No ano de 2016, a Gol Linhas Aéreas Inteligentes assumiu a liderança do mercado doméstico em termos de demanda com 36,0\%, de participação. A Latam deteve 34,7\% e as companhias Azul e Avianca obtiveram 17,1\% e 11,5\%, respectivamente. Segundo dados da agência reguladora, a Latam foi a única empresa que apresentou queda na participação no mercado doméstico, registrando uma redução de 5,3\% em relação ao ano de 2015, enquanto Gol, Azul e Avianca obtiveram crescimento de 0,2\%, 0,5\% e 
21,4\%, respectivamente (ANAC, 2017). Esses dados de participação de mercado podem ser compreendidos, numa perspectiva geográfica, pela atuação dessas companhias no território nacional.

A principal companhia que tem definido essa lógica no sentido de atender a escala regional acirrando a concorrência com a Azul é companhia Gol, como é possível observar no comparativo das Figuras 8 e 9, o que demonstra uma rarefação na Região Concentrada e uma ampliação, ainda que tímida (se comparado a Azul), na escala regional.

A Avianca mantém sua atuação na escala regional, sobretudo nas Regiões Nordeste e Centro-Oeste, sem alterar drasticamente sua topologia de malhas, mas mantendo sua presença nessa escala.

Quanto a Tam, por uma opção estratégica, após sua fusão com a Lan e a criação da Latam, tem articulado uma topologia mais incisivamente na escala internacional, o que fez com que a empresa continuasse presente em todas as escalas, mas com uma diminuição considerável de suas rotas no território nacional, priorizando voos que funcionam como "alimentadores" da escala internacional, ou seja, geradores de fluxos e passageiros que tem como destino final outros países.

Temos com isso a compreensão de que a redefinição do poder territorial no setor aéreo brasileiro tem conferido, cada vez mais, um novo mapa de atuação territorial no Brasil, que segue uma lógica competitiva, em que a estratégia articula a dinâmica do capital à uma dinâmica territorial. Estrategicamente a companhia Azul inseriu-se no mercado com uma proposta inovadora em termos de poder de mercado, o que refletiu territorialmente uma ação articulada de movimentação de uma demanda ociosa à espera de oferta, o que nos demonstra uma nova topologia da malha aérea no território brasileiro, a qual incluiu novos e importantes pontos nessa rede aérea do país.

O que podemos observar e tirar como comparativo é que historicamente o setor de transporte aéreo no Brasil tem reorientado a lógica de mercado versus a lógica territorial. Enquanto que a Varig sucumbiu, boa parte, em razão de uma escolha estratégica pelo mercado internacional num processo quase que em detrimento do mercado nacional/regional, as companhias aéreas na atualidade, apesar de almejarem uma atuação internacional, centralizam seus voos usando o território brasileiro como base essencial para alçar novos e mais distantes voos.

\section{Considerações finais}

Histórica e geograficamente as companhias aéreas distribuíam seus voos partir dos principais hubs aeroportuários estabelecendo uma rede de fluxos que definia, em grande medida, seus interesses mediante uma lógica de poder territorial. Essa centralização, do ponto de vista estratégico é óbvia, uma vez que estes fixos aeroportuários são aqueles de maior poder de geração de tráfego, em outras palavras, é onde se verifica a maior reprodução ampliada do capital.

No entanto, produto desse processo globalizante que permite uma maior flexibilidade do mercado no que diz respeito a circulação, a materialização dos fluxos de pessoas em diferentes lugares se torna uma prerrogativa cada vez mais impositiva, já que o modal aéreo tem aumentado seus nichos de mercado devido sua maior utilização. 
Com isso, apresentamos nesse texto uma nova leitura sobre a topologia da malha aérea brasileira. Nota-se hoje uma nova lógica do capital na relação com o uso do território nas diferentes escalas.

Ainda que a Região Concentrada do país detenha a centralização dos voos mais movimentados, demais rotas têm promovido uma rearticulação territorial, descentralizando as ligações dessa área, não, obviamente, no sentido de exclui-las da rede fluxos, mas sim no sentido de criar novos pontos de articulação a partir de outros aeroportos por meio de ligações diretas.

Cria-se com isso um novo mapa de atuação no território brasileiro, que tem como lógica favorecer o "descongestionamento aéreo", verificado nos principais hubs do setor no Brasil. Dentro dessa perspectiva geográfica, assistimos a configuração de uma organização topológica das linhas aéreas condicionada pelos interesses do capital que impele um posicionamento estratégico das companhias nacionais líderes.

Tal configuração tem um rebatimento territorial no qual se verifica outros resultados, tais como: uma nova e diferenciada estratégia (ao menos a priori) da companhia Azul e perseguida pelas demais em menor escala, o que por consequência amplia a capilaridade das malhas na escala nacional. Além disso, nota-se também transformações nas dinâmicas de competitividade em razão do próprio rearranjo das malhas. Embora se perceba uma concentração de mercado (Latam, Gol e Azul), que marca uma centralização operacional dos players, assistimos hoje uma maior mobilidade dos pontos de operação aérea, o que não se verificava antes com o monopólio das companhias e o engessamento NorteSul das malhas aéreas que tinha como hubs principais os aeroportos da Região Concentrada.

Portanto, quando tratamos das escalas territoriais no setor de transporte aéreo brasileiro, é preciso compreender que nem sempre há uma relação hierárquica de importância em termos territoriais entre regional, nacional e internacional. Quando uma estratégia é eloquentemente exequível pode reconfigurar a malha de voos nas diferentes escalas territoriais, uma vez que está invólucro às estratégias empresariais um território de uso competitivo, isso porque o território é sensível, nervoso e objeto de numerosas mudanças de conteúdo (Santos e Silveira, 2004:271). Em síntese, a estratégia pode não ser inédita, mas é sempre circunstancial do momento e do interesse do capital por um maior poder territorial. 


\section{Q Bibliografia}

》 Agência Nacional DaAviação Civil/Anac.(2017). Anuários Estatísticos(Vários anos). Brasil, Rio de Janeiro.

" Camilo Pereira, A. P. (2016). Asas da centralidade em céus conhecidos: a dinâmica empresarial do transporte aéreo no território brasileiro. São Paulo: Annablume.

»Chesnais, F. (1996). A Mundialização do Capital. São Paulo: Xamã Editora.

» Guaracy, T. (2003). O sonho brasileiro. Como Rolim Adolfo Amaro criou a Tam e sua filosofia de negócios. São Paulo: A Girafa.

»Leroy, F. (2004). Les strategies de l'entreprise. Paris: Dunod, $2^{\mathrm{a}}$ edição.

" Monteiro, C. F. (2007). A VARIG e o Brasil entre o desenvolvimento acional e a competitividade global. Civitas Revista de Ciências Sociais 7 (1), 35-58.

»Porter, M. (1986). Estratégia competitiva. Técnicas para análise de indústrias de concorrência, BRAGA, E. M. P. de (Trad.). Rio de Janeiro: Campus.

»Santos, M. (1994). O retorno do território. In: M. Santos, M. A. Souza, M. L., Silveira. Território: globalização e fragmentação. São Paulo: Hucitec.

"Santos, M. y Silveira, M. L. (2004). Brasil: território e sociedade no início do século $X X I$. Rio de Janeiro: Record.

»Théry, H. (2003). O transporte aéreo no Brasil: asas da centralidade. Mercator Revista de Geografia da UFC 2 (3), 19-25.

\section{Sites}

» Rotas da Varig. Disponível em: http://www.varig-airlines.com/pt/rotas.htm Acesso em: 01/02/2018.

\section{Ana Paula Camilo Pereira / apaulacape@uems.br - apaulacape@uems.br}

Doutora em Geografia Humana pela Universidade de São Paulo (USP). Doutorado Sanduíche pela Université Sorbonne Nouvelle Paris III (França). Mestre em Geografia pela Universidade Estadual Paulista (UNESP). Licenciada e Bacharel em Geografia pela Universidade Federal da Grande Dourados (UFGD). Docente do curso de Geografia (Licenciatura e Bacharelado) e do Programa de Pós-Graduação Stricto Sensu Mestrado Profissional em Educação da Universidade Estadual de Mato Grosso do Sul (UEMS).

\section{Hervé Théry / hthery@aol.com - herve.thery@usp.br}

Graduado em História e Geografia pela Université Paris 1 (Panthéon - Sorbonne). Mestre em Geografia pela Université Paris 1 (Panthéon - Sorbonne). Doutor em Geografia pela Université Paris 1 (Panthéon - Sorbonne) e Habilitation à diriger des recherches (Livre Docência), pela Université Paris X Nanterre (França). Pesquisador do Centre National de la Recherche Scientifique - CNRS, professor visitante da Universidade de São Paulo (USP) e pesquisador convidado da Universidade de Brasília (CDS). Coordenador editorial da revista Confins. 